Article

\title{
Experiment and Simulation of Medium-Duty Tactical Truck for Fuel Economy Improvement
}

\author{
Yeau-Jian Gene Liao ${ }^{1, *}$ and Allen M. Quail Jr. ${ }^{2}$ \\ 1 Wayne State University, 4855 Fourth St., Detroit, MI 48202, USA \\ 2 ASRC-WTSI, Inc. / 35660 Beattie Dr., Sterling Heights, MI 48312, USA; \\ E-Mail: allen.quail@asrcwtsi.com \\ * Author to whom correspondence should be addressed; E-Mail: geneliao@wayne.edu; \\ Tel.: +1-313-577-8078; Fax: +1-313-577-1789.
}

Received: 26 November 2010; in revised form: 5 January 2011 / Accepted: 26 January 2011 / Published: 4 February 2011

\begin{abstract}
Fuel economy improvement on medium-duty tactical truck has and continues to be a significant initiative for the U.S. Army. The focus of this study is the investigation of Automated Manual Transmissions (AMT) and mild hybridization powertrain that have potential to improve the fuel economy of the 2.5-ton cargo trucks. The current platform uses a seven-speed automatic transmission. This study utilized a combination of on-road experimental vehicle data and analytical vehicle modeling and simulation. This paper presents the results of (1) establishment of a validated, high fidelity baseline analytical vehicle model, (2) modeling and simulation of two AMTs and their control strategy, (3) optimization of transmissions shift schedules, and (4) modeling and simulation of engine idle stop/start and Belt-Integrated-Starter-Generator (B-ISG) systems to improve the fuel economy. The fuel economy discrepancy between experimental average and the baseline simulation result was $2.87 \%$. The simulation results indicated a $14.5 \%$ and $12.2 \%$ fuel economy improvement for the 10-speed and 12-speed AMT respectively. A stop/start system followed by a B-ISG mild hybrid system incorporating regenerative braking was estimated to improve fuel economy $3.39 \%$ and $10.2 \%$ respectively.
\end{abstract}

Keywords: AMT; automated manual transmission; fuel economy; transmission shift schedule; tactical truck 


\section{Introduction}

The U.S. Government owns and maintains a large fleet of ground vehicles covering a wide spectrum of mission profiles. The cost to supply each vehicle with fuel during peacetime is staggering and becomes more so under war zone conditions. The fuel represents more than half of the logistics tonnage of the Department of Defense (DoD), and more than $70 \%$ of the tonnage required to put the U.S. Army into position for battle [1]. The DoD estimates that 40,000 Army personnel involved in either the distribution or movement of energy [2]. Not to mention only two out of the top ten battlefield fuel consumers in the U.S. Army are combat vehicles and the other eight carry fuel and supplies. Over half of the fuel transported to the battlefield is consumed by support vehicles, not vehicles engaged in frontline combat [3]. The impact of the vehicle fuel economy in military applications is amplified due to the fact that much of the present logistics support is devoted to moving fuel. It is critical to improve the fuel economy of those vehicles that play an important role in the U.S. Army tactical vehicle fleet.

The Family of Medium Tactical Vehicles (FMTV) has 14 variations of 2.5-ton and 5-ton truck, and continues to be the highest percent availability of any vehicle in the U.S. Army tactical vehicle fleet [4]. The most common version of the FMTV is the Light Medium Tactical Vehicle (LMTV), a high mobility 2.5-ton class payload $4 \times 4$ diesel powered truck as shown in Figure 1. Basically, the LMTVs perform unit mobility and unit resupply missions including the transport of equipment and personnel. The vehicle specifications are listed in Table 1 [5]. Commonality of chassis and powertrain components between the vehicles in the LMTV allow improvements to the target vehicle to have the potential to benefit the entire fleet.

Figure 1. LMTV M1078 A1.

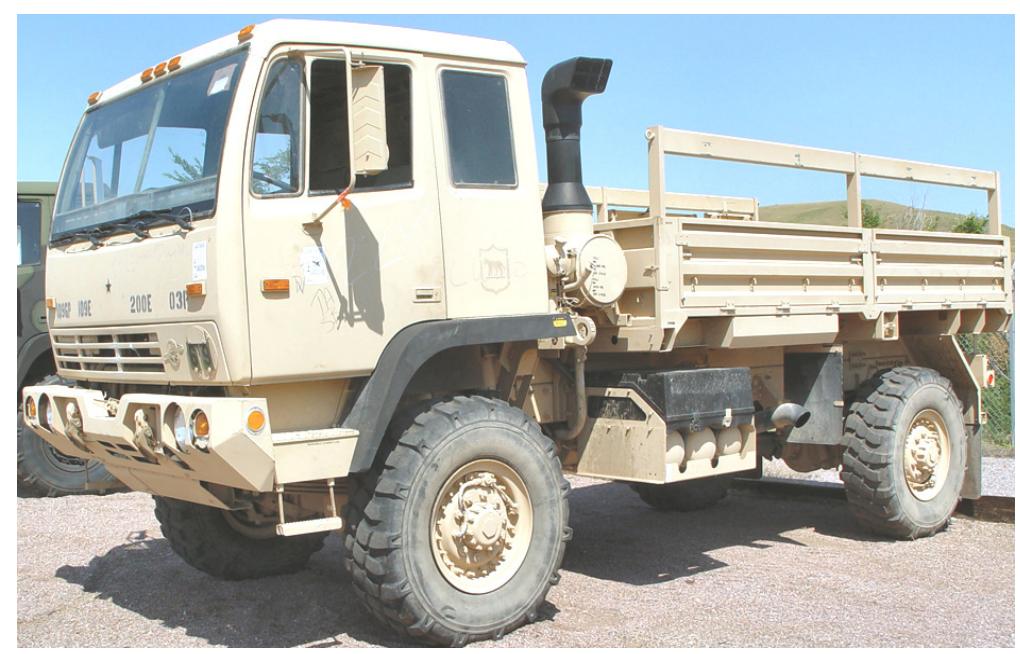

The current LMTV platform uses a seven-speed automatic transmission (AT). An AT is convenient to use but it has relatively higher fuel consumption. A Manual Transmission (MT) is relatively fuel efficient with typically $10 \%$ better fuel economy than AT [6,7], but it is not easy to operate. Combining the benefits of both AT and MT, an Automated Manual Transmission (AMT) represents a promising solution since it can be considered as an inexpensive add-on solution for classical MT systems. An AMT is actually a MT with an add-on control unit that automates the clutch and shift 
operations. An AMT provides the same user interface as an AT, i.e., accelerator and brake pedals but no clutch. A vehicle equipped with AMT can be operated in the same way as a vehicle with AT, but the fuel economy will be highly improved compared with the AT [6-10]. This fuel economy improvement is not from gear meshing efficiency because it is the same for all types of transmissions but due to the gear shift schedule. An AMT is able to shift to a higher gear earlier while the MT has to stick with a mandatory gear schedule. At highway cruise the AMT will be no better than the MT. It may be slightly worse if parasitic losses are present to operate a hydraulic pump continuously $[6,8]$.

The mild hybrids provide limited functions, such as engine stop/start and regenerative braking energy capture. The "mild" means that the vehicle uses a relatively small motor for torque assist of the engine. Belt-Alternator-Starter (BAS) system [11,12] or Belt-Integrated-Starter-Generator (B-ISG) [13] and Flywheel-Alternator-Starter (FAS) [14], Crankshaft-Integrated-Starter-Generator (C-ISG) [15], or Integrated-Motor-Assist (IMA) systems [16,17] are currently available mild hybrid powertrains. The B-ISG system replaces the standard alternator with an electric motor/generator that is connected to the ICE via a belt or chain. The system enables early fuel cut-off during deceleration and shut off of the engine during idle. It operates in two modes: (1) motoring-provides cranking torque to restart the engine when the brake pedal is released and to assist vehicle acceleration; (2) generating - charges the battery when the engine is running. The battery provides electric power to run vehicle accessories and passenger comfort systems while the engine is off. Regenerative braking capabilities are also included to further enhance fuel economy. The B-ISG system strikes a compromise between fuel efficiency and price. It is designed to fit in the same space as a typical engine and work with conventional transmissions to minimize integration effort and cost. Figure 2 illustrates a typical B-ISG system layout.

Figure 2. Layout of a typical B-ISG system [12].

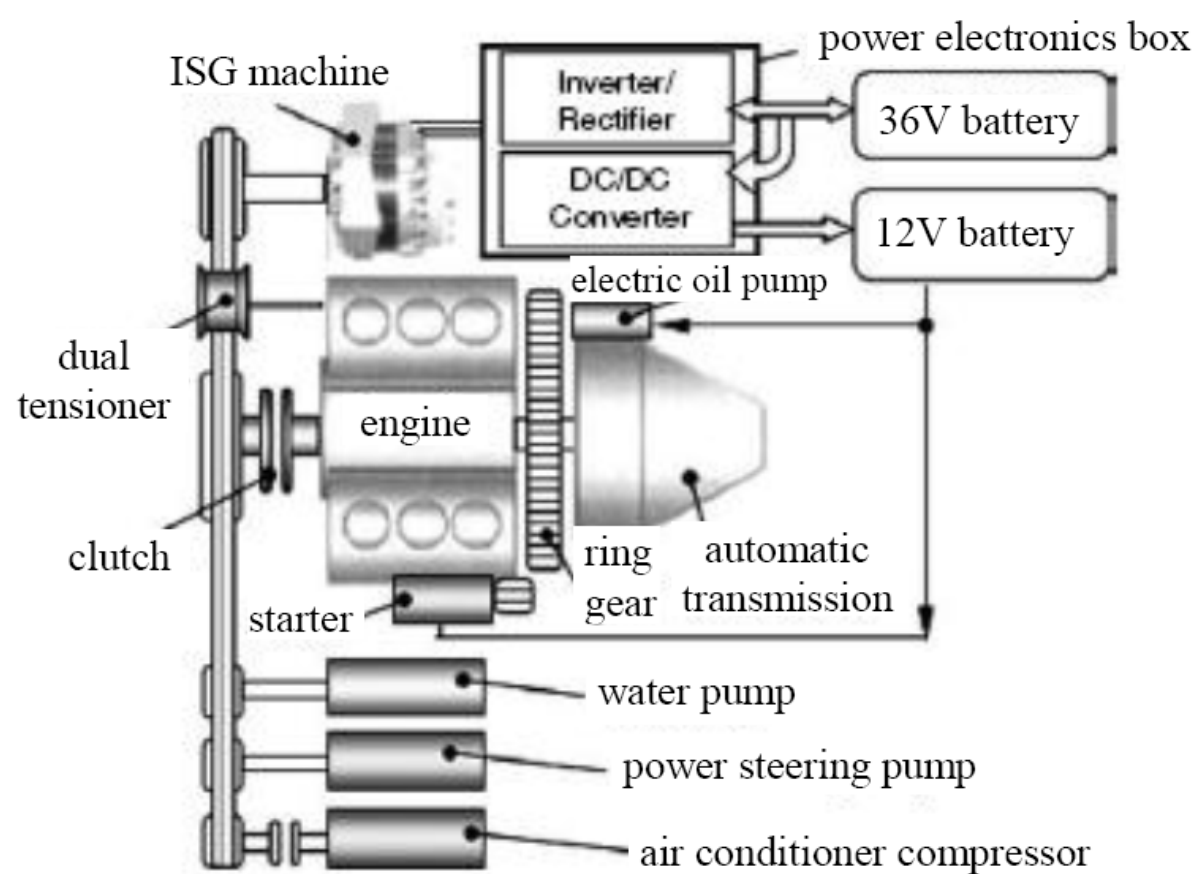

The focus of this study is the feasibility analysis and evaluation of AMT and mild hybridization powertrain that have potential to improve the fuel economy of the truck. The two AMTs evaluated in the study were 10-speed and 12-speed. The powertrain hybridization included a stop/start system 
followed by a B-ISG mild hybrid system. A combination of on-road experimental vehicle data and analytical vehicle modeling and simulation were used in the study. Considerations such as packaging, durability or manufacturing were outside the scope of this study. This paper presents the results of (1) establishment of a validated, high fidelity baseline analytical vehicle model, (2) modeling and simulation of two AMTs and their control strategy, (3) optimization of transmissions shift schedules, and (4) modeling and simulation of engine idle stop/start and B-ISG systems to improve the fuel economy. This paper gives a detail description of experiment, simulation, and correlation results partially based on Van Benschoten and Nelson [18].

Table 1. LMTV M1078 A1 vehicle description [5].

\begin{tabular}{|c|c|}
\hline Vehicle Component & Specification \\
\hline Wheel base & $3900 \mathrm{~mm}\left(153.5^{\prime \prime}\right)$ \\
\hline Vehicle curb weight (no kits, crew, fuel) & $7809 \mathrm{~kg}(17,216 \mathrm{lb})$ \\
\hline Payload & $2268 \mathrm{~kg}(5000 \mathrm{lb})$ plus kits \\
\hline Towed load & $5443 \mathrm{~kg}(12,000 \mathrm{lb})$ \\
\hline $\begin{array}{l}\text { Maximum speed } \\
\text { (governed, at gross weight) }\end{array}$ & $94 \mathrm{kph}(\mathrm{km} / \mathrm{h})$ or $58 \mathrm{mile} / \mathrm{h}(\mathrm{mph})$ \\
\hline Range -58 gal (219 L) nominal & $645 \mathrm{~km}$ (400 mile) \\
\hline Maximum grade/side slope & $60 \% / 30 \%$ \\
\hline Engine: & $\begin{array}{l}\text { Caterpillar C7 ATAAC (air-to-air after } \\
\text { cooler) HD diesel, in-line 6-cylinder, } \\
\text { 4-stroke-cycle }\end{array}$ \\
\hline Displacement & $7.2 \mathrm{~L}$ (441 cubic inch) \\
\hline Aspiration & $\begin{array}{l}\text { Turbocharged-air-to-air aftercooler, } \\
\text { EPA } 07 \text { certified }\end{array}$ \\
\hline Rating & 205 kW (275 hp)@2600 rpm \\
\hline Torque & 1166 Nm (860 lb-ft)@1440 rpm \\
\hline Fuel system & Electronic injection \\
\hline Fuel types & Diesel, DF-2, JP-4, JP-8 \\
\hline Transmission: & $\begin{array}{l}\text { Allison } 3700 S P, 7 \text {-speed automatic, } \\
\text { electronically controlled, full-time } \\
\text { all-wheel drive }\end{array}$ \\
\hline Front wheels & $30 \%$ torque \\
\hline Rear wheels & $70 \%$ torque \\
\hline Axles: Front/rear axles & ArvinMeritor \\
\hline Overall axle gear ratio & $7.8: 1$ \\
\hline
\end{tabular}

\section{Analytical Vehicle Model and Experimental Test of Baseline Vehicle}

The vehicle modeling and simulation allows the exploration of design space to study numerous combinations in the fuel economy. Simulation software packages can provide convenience and flexibility for integrating technology and produce evaluated results for different configurations of the vehicle drivetrain. Experimental test was conducted to collect real world vehicle data to correlate and validate the analytical vehicle model. 


\subsection{Baseline Vehicle Model}

Vehicle simulation model can be generally classified as two types: kinematic and dynamic methods. In the kinematic method, the force required to accelerate the vehicle through the time step is calculated directly from the required speed trace. The required force is then translated into a torque that must be provided by the component directly upstream. This power/energy requirement at the wheel is passed backward through all the powertrain components to compute fuel and electricity consumption. The dynamic method is solved forward approach where the desired vehicle speed is an input to the driver/PID controller which actuates the accelerator position therefore requesting torque from the powertrain which in turn produces a response through the driveline. This method is more realistic in that it controls the engine similar to the way an actual driver does and does not directly control the driveline components. The adjustment of the driver/PID determines how accurately the vehicle model follows the desired vehicle speed trace. Although both kinematic and dynamic methods were evaluated in this project, it was determined that the dynamic method produced the most realistic results.

The GT-Drive software [19] was used for the vehicle modeling and simulation in this project. For this study a relatively simple approach was taken that uses steady state engine performance maps to determine fuel rate for a desired engine torque at a given engine speed. It has been shown that fuel economy can be accurately predicted using simple steady state engine maps [20,21]. The vehicle model also requires considerable driveline information: clutch and torque converter performance tables; transmission gear ratios, inertias, efficiencies and shift schedule; transfer case gear ratio, inertias and torque distribution on the front and rear axles; drive shaft and axle inertias; final drive gear ratio and inertias; tires radius and rolling resistances; braking torque maps; and any other data related to vehicle resistances such as aerodynamic drag force. Other control algorithms were added to the model for simulating an engine idle speed controller and a simple fuel shutoff control during deceleration events. A layout GT-Drive model is presented in Figure 3.

\subsection{Baseline Vehicle Experimental Testing}

Experimental test was performed to collect actual vehicle data to correlate and validate the analytical vehicle model. Coast-down testing and fuel economy drive cycle was performed. The test vehicle was instrumented to collect among other information: engine speed, vehicle speed, accelerator pedal position, manifold pressure, transmission gear position, fuel flow rate, and wind speed and direction. The wind sensor was mounted $3 \mathrm{~m}$ in front of the vehicle at approximate half of its height $(1.4 \mathrm{~m})$. The wind speed/direction sensor was installed in an area where it was not influenced by the boundary layer created around the moving vehicle. The tripod-like frame that sustains the wind sensor instrument was made in such way to minimize its contribution to the overall aerodynamic drag. Instrumented vehicle test weight and daily weather data were also acquired. The baseline vehicle instrumentation is shown in Figure 4. 
Figure 3. GT-Drive model of the conventional LMTV truck. (a) Powertrain model; (b) Vehicle model.

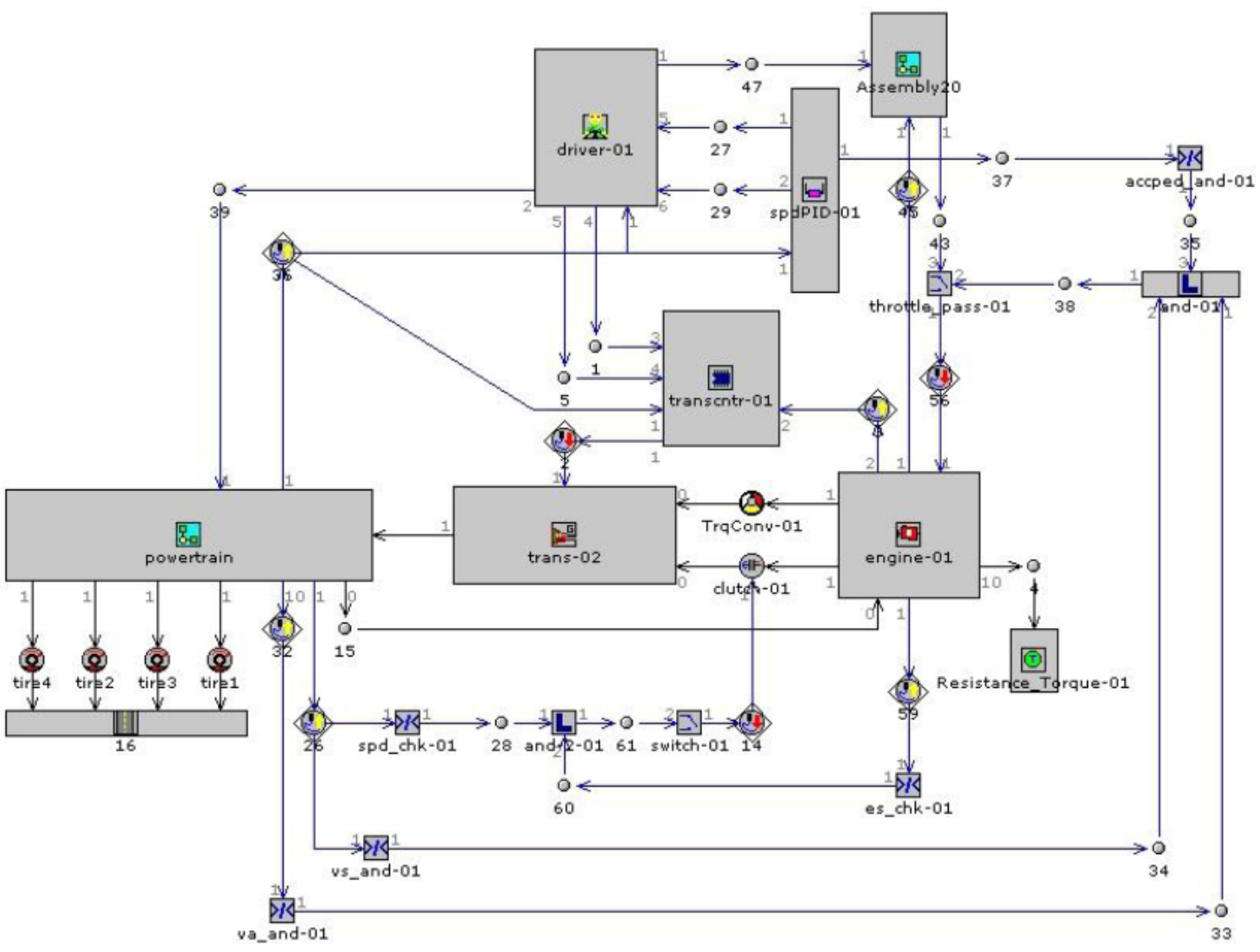

(a)

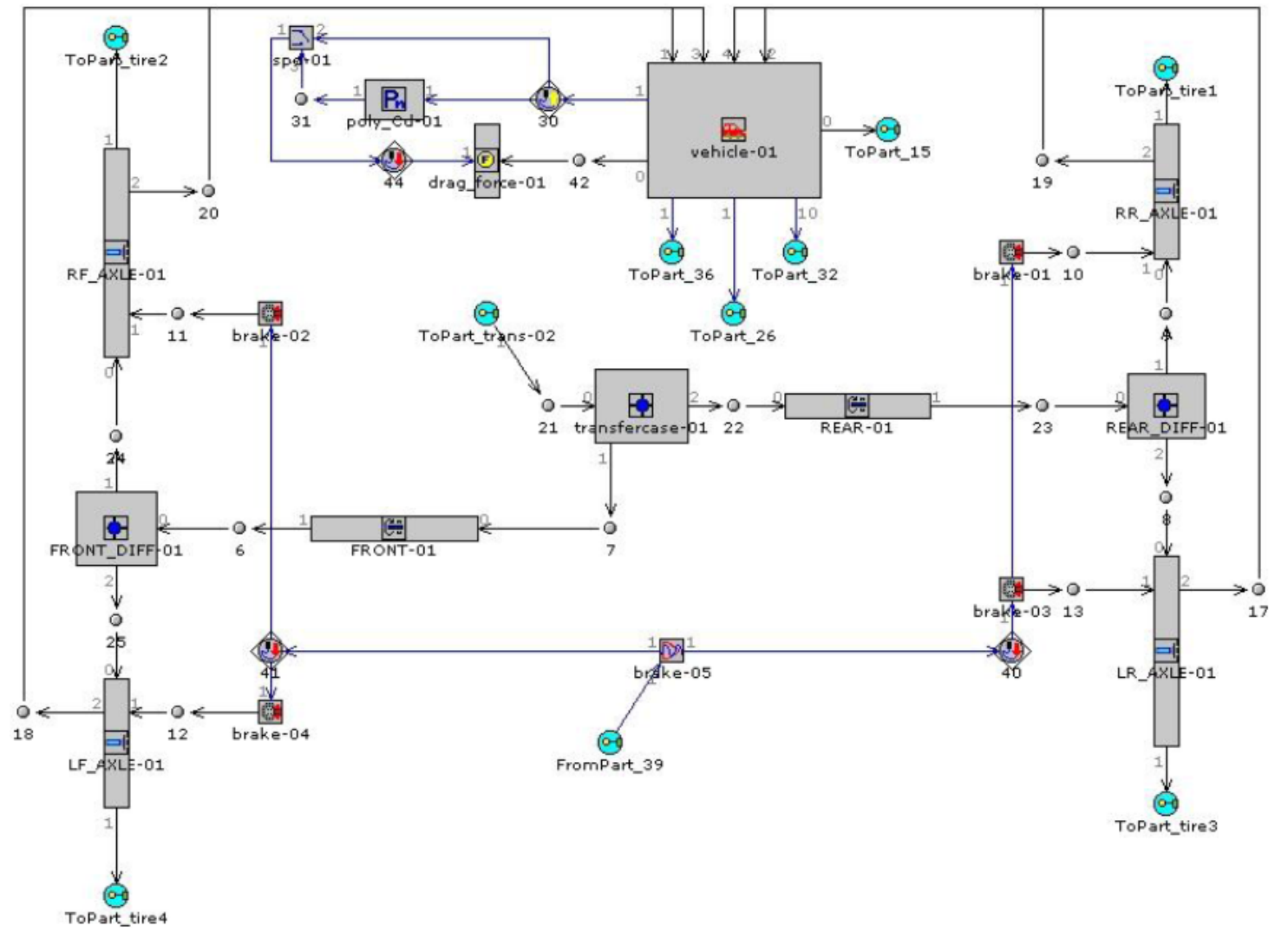

(b) 
Figure 4. Vehicle instrumentation. (a) Fuel flow meter installation; (b) Data acquisition instrumentation; (c) Wind sensor installation.

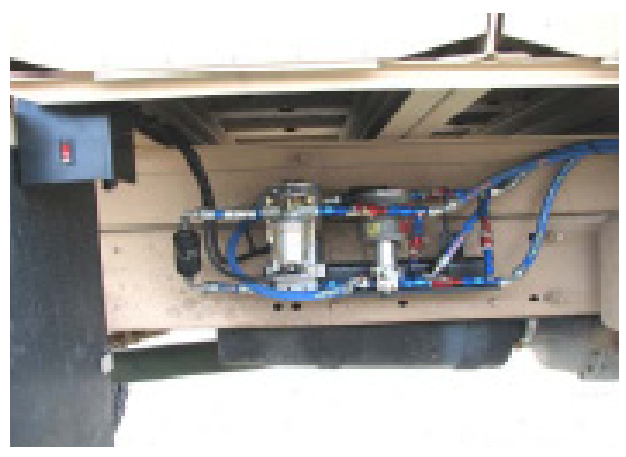

(a)

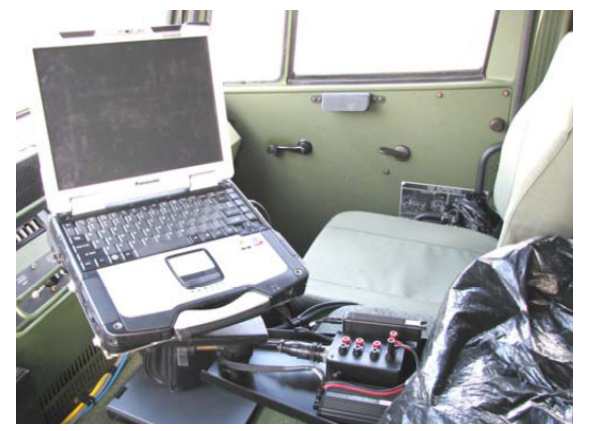

(b)

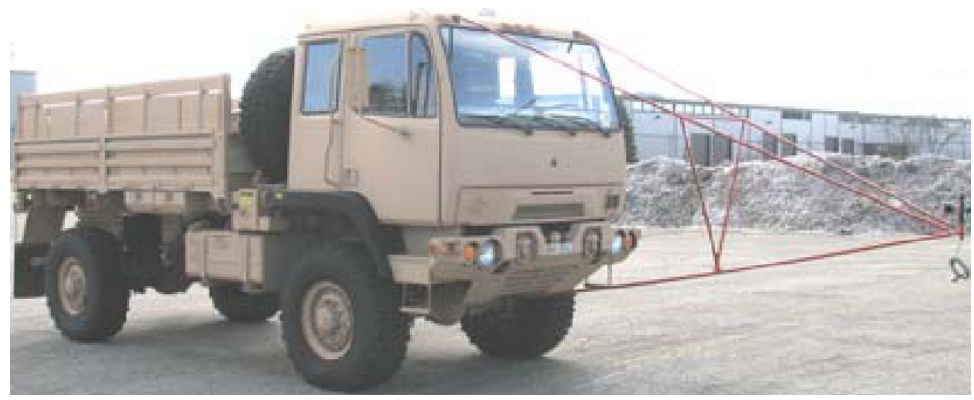

(c)

Coast-Down Testing Coast-down testing was performed to compute the road load acting on the vehicle. In this test, the vehicle was accelerated to a desired speed, transmission was shifted to neutral gear and then the vehicle was decelerated under the action of various resistance forces. The general form of the equation of motion for coast-down testing is:

$$
M_{e} \cdot \frac{d V_{v e h}}{d t}=D_{r}+D_{a}+D_{g}
$$

where $M_{e}$ is effective vehicle mass, $V_{\text {veh }}$ is vehicle speed $\mathrm{kph}(\mathrm{km} / \mathrm{h}), D_{r}$ is rolling resistance force, $D_{a}$ is aerodynamic drag force, and $D_{g}$ is gravity force.

$$
M_{e}=M_{v e h}+\frac{I_{f}+I_{r}}{R^{2}}
$$

where $M_{v e h}$ is vehicle mass $(\mathrm{kg}), I_{f}$ and $I_{r}\left(\mathrm{~kg}-\mathrm{m}^{2}\right)$ is the moment inertia of the front and rear axle respectively, and $R$ is tire rolling radius (m). The second term in Equation (2) is the effective mass of the rotating components, which represent the inertia of the rotating components expressed as additional linear mass. Based on a linear mass $M_{v e h}$ of $8402 \mathrm{~kg}$, the moment inertia of the front axle $\left(I_{f}\right.$, $\left.102.8 \mathrm{~kg}-\mathrm{m}^{2}\right)$ and rear axle $\left(I_{r}, 126.8 \mathrm{~kg}-\mathrm{m}^{2}\right)$, and an effective wheel rolling radius of $574 \mathrm{~mm}$; the total effective vehicle mass $M_{e}$ is $9099 \mathrm{~kg}$. This value does not include the rotational mass of the transmission or the engine. The value of effective mass calculated above was used for calculating road load coefficients during coast-down testing per SAE J2263.

$$
D_{r}=\alpha_{r}+\beta_{r} \cdot V_{v e h}+\gamma_{r} \cdot V_{v e h}^{2}
$$


where $\alpha_{r}, \beta_{r}$ and $\gamma_{r}$ are rolling resistance coefficients. The rolling resistance force is calculated as a second degree function of vehicle speed [22]. The complex relationships between the design and operational parameters of the tire and its rolling friction make it difficult to development an analytical method for predicting the rolling resistance of a vehicle. Therefore the determination of the rolling resistance relies almost entirely on experiments. Based on experimental results, many empirical formulas have been provided for calculating the rolling resistance, which may be found in the SAE handbook. The aerodynamic drag was not taken into account in calculating the rolling resistance. The aerodynamic drag is calculated as a fourth degree function of yaw angle and second degree function of relative wind speed [23].

$$
D_{a}=\frac{1}{2} \cdot p_{\text {air }} \cdot A_{\text {frontal }} \cdot V_{w}^{2} \cdot\left(a_{0}+a_{1} \cdot Y+a_{2} \cdot Y^{2}+a_{3} \cdot Y^{3}+a_{4} \cdot Y^{4}\right)
$$

where $p_{\text {air }}$ is air density in $\mathrm{kg} / \mathrm{m}^{3}, A_{\text {frontal }}$ is frontal area, $V_{w}$ is relative wind speed $(\mathrm{km} / \mathrm{h}), Y$ is wind yaw angle, $a_{0}, a_{1}, a_{2}, a_{3}$, and $a_{4}$ are aerodynamic drag coefficients. The gravitational is a function of slope and vehicle mass.

$$
D_{g}= \pm M_{e} \cdot g \cdot \frac{d H}{d L}
$$

where $g$ is acceleration of gravity, $H$ is the height, and $L$ is the horizontal traveling distance.

The above equations are based on the following assumptions:

- The decrease in the aerodynamic drag due to lift forces is very small and disregarded.

- The tire slip angle due to aerodynamic side forces and yawing moments are negligible and do not influence the tire rolling resistance.

- The variation of the rolling resistance with vehicle speed can be adequately modeled with a second degree function of vehicle speed.

- The variation of the aerodynamic drag coefficient over the speed range of the test is negligible.

- The variation of the aerodynamic drag coefficient with yaw angle can be adequately modeled with a fourth degree function of yaw angle.

The coast-down test was performed on an oval track at the proving ground. On this track, the straight road portion was approximately $1.6 \mathrm{~km}$ long and the radius of the curved portion was approximately $0.8 \mathrm{~km}$. There was no slope on either straight portion of the track.

Driving Cycle The U.S. FTP-72 (Federal Test Procedure) cycle was used for the fuel economy test. This cycle is also called the Urban Dynamometer Driving Schedule (UDDS) or LA-4 cycle [24]. The cycle represents an urban route of $12.07 \mathrm{~km}(7.5 \mathrm{mi})$ with frequent stops. The maximum speed is $91.2 \mathrm{~km} / \mathrm{h}(56.7 \mathrm{mi} / \mathrm{h})$ and the average speed is $31.5 \mathrm{~km} / \mathrm{h}(19.6 \mathrm{mile} / \mathrm{h})$.

\subsection{Correlation between Simulation and Experimental Baseline Vehicle}

Creation of the baseline analytical vehicle model and correlation its simulation results with the experimental data is the first step in the modeling process. It is necessary to ensure that simulation results closely matched the experimental results by adjusting the vehicle modeling parameters. Three primary areas were investigated to correlate and validate the analytical model: road load, transmission shift schedule over cycle, engine torque and vehicle speed over the driving cycle. 
Road Load Correlation The accuracy of simulated fuel economy is mainly affected by road load calculation. If the calculated road load is different from the experiment, it leads to inaccuracy in the fuel economy calculations because the required engine torque to propel the vehicle through the driving cycle would be higher or lower than actual required. Coast-down tests were performed to validate the road load. The comparison of coast-down time from vehicle speed $90 \mathrm{kph}$ to $20 \mathrm{kph}$ is shown in Table 2. The error between the simulated and experimental data can vary based on the corresponding experimental data set chosen. The experimental variation was due primarily to the difference in side and head winds present during each experimental run. The coast-down simulation assumes ideal environmental conditions which do not exist in the experimental tests. The test with the best environmental conditions is shown in Figure 5. This test had the smallest amount of overall error with only $3 \%$ of the points outside the $\pm 5^{\circ}$ yaw angle range and $17 \%$ outside the relative wind speed range of $\pm 5 \mathrm{kph}$. After examining the experiments data, the average of the filtered coefficients from experiments determined the rolling resistance coefficients in Equation (3): $\alpha_{r}=819.135 \mathrm{~N}$, $\beta_{r}=18.3576 \mathrm{~N} / \mathrm{kph}, \gamma_{r}=0.30751 \mathrm{~N} / \mathrm{kph}^{2}$. These values were used in the simulation of FTP-72 drive cycle.

Figure 5. Coast-down correlation.

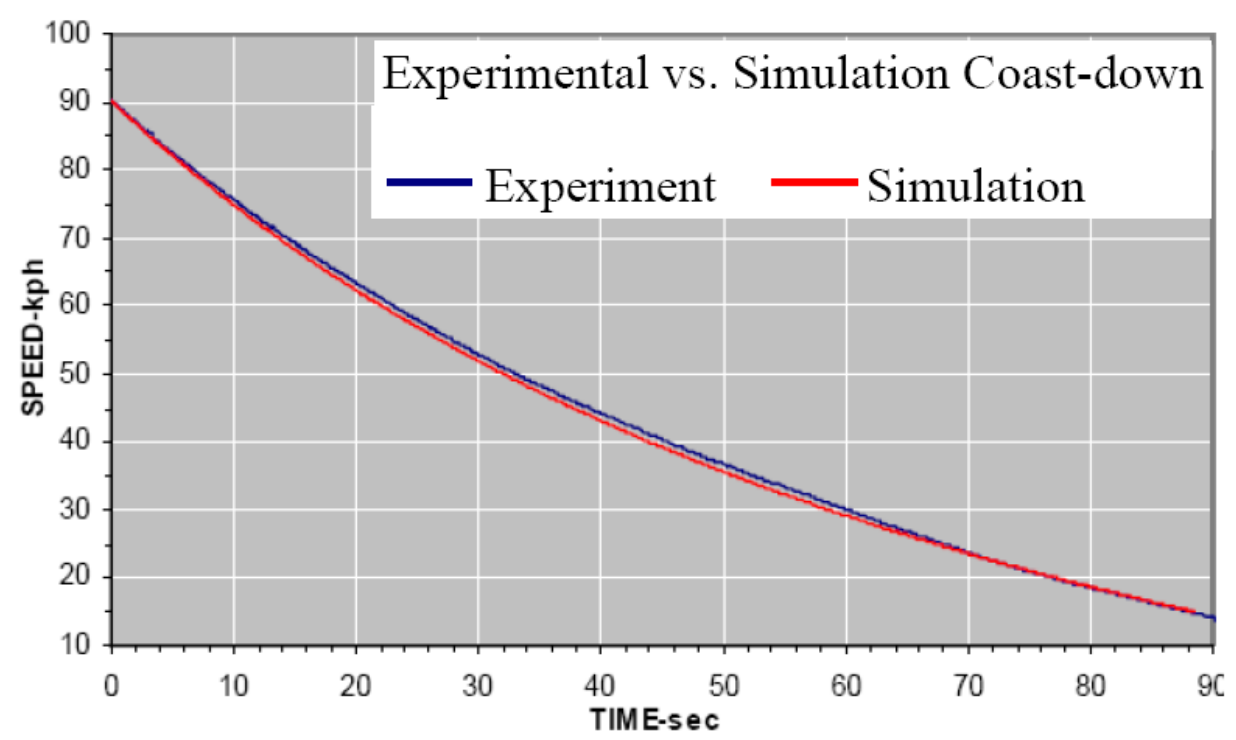

Transmission Shift Schedule Correlation The baseline LMTV is equipped with an Allison seven-speed AT. Baseline shift schedule is needed to match the experimental data for correlation. Experimental data was statistically evaluated in each gear to determine the mean speeds at which up-shift and down-shift occurred. Table 3 lists the gear ratio, inertia, efficiency, and shift schedule of the baseline seven-speed AT. These data are required in the simulation.

Engine Torque and Vehicle Speed Correlation Based on the correlations of the road load and transmission shift schedule, it needs to adjust the vehicle driver model with PID controller to achieve simulated engine torque, engine speed and vehicle speed similar to the experimental data. A design of experiments method was set-up to evaluate the model response to various PID configurations. The primary goals were to reduce torque fluctuations and to provide the best vehicle speed trace matching. Preliminary comparison of simulation and experimental results indicated an initial PID value of 
(10-0.1-0). After further investigation, a PID value of (40-0.4-0) was chosen for the remainder of the study. This larger gain produced better vehicle speed matching. Torque smoothing was not as good as with the (40-0.4-0) PID but still aligned well with the experimental data. Figure 6 shows the examples of comparisons between simulation and experiment results using these PID values.

Table 2. Comparison of coast-down time between experiment and simulation.

\begin{tabular}{ccccc}
\hline Run No. & $\begin{array}{c}\text { Test Time } \\
\text { (sec) }\end{array}$ & $\begin{array}{c}\text { Simulation } \\
\text { Time (sec) }\end{array}$ & $\begin{array}{c}\Delta \text { T } \\
\text { (Simulation Time }- \text { Test Time) }\end{array}$ & $\begin{array}{c}\text { \% Error } \\
(\Delta \text { T/Test Time) }\end{array}$ \\
\hline 1 & 75.8 & 76.672 & 0.872 & $1.1 \%$ \\
2 & 84.3 & 79,104 & -5.196 & $-6.6 \%$ \\
3 & 74.1 & 72.704 & -1.396 & $-1.9 \%$ \\
4 & 78.8 & 77.056 & -1.744 & $-2.3 \%$ \\
5 & 76.6 & 76.928 & 0.328 & $0.4 \%$ \\
6 & 77.1 & 75.648 & -1.452 & $-1.9 \%$ \\
7 & 73.0 & 75.264 & 2.264 & $3.0 \%$ \\
8 & 75.8 & 73.856 & -1.944 & $-2.6 \%$ \\
9 & 72.0 & 67.328 & -4.672 & $-6.9 \%$ \\
\hline
\end{tabular}

Table 3. Data of baseline seven-speed AT. (a) Gear ratio and efficiency; (b) Based shift schedule.

\begin{tabular}{|c|c|c|c|c|}
\hline Gear No. & Gear Ratio & Gear Ratio Step Fraction & Inertia $\left(\mathrm{kg} \mathrm{m}^{2}\right)$ & Efficiency \\
\hline 1 & 6.93 & 1.658 & 0.16 & 0.954 \\
\hline 2 & 4.18 & 1.866 & 0.17 & 0.961 \\
\hline 3 & 2.24 & 1.325 & 0.20 & 0.971 \\
\hline 4 & 1.69 & 1.408 & 0.23 & 0.975 \\
\hline 5 & 1.20 & 1.333 & 0.34 & 0.980 \\
\hline 6 & 0.90 & 1.154 & 0.46 & 0.980 \\
\hline 7 & 0.78 & & 0.66 & 0.980 \\
\hline
\end{tabular}

(a)

\begin{tabular}{ccccccc}
\hline \multicolumn{7}{c}{ Vehicle Speed Based Shift Schedule } \\
\hline Up-shift event & $1-2$ & $2-3$ & $3-4$ & $4-5$ & $5-6$ & $6-7$ \\
Vehicle speed (kph) & & 11.05 & 28.23 & 22.46 & 33.67 & 53.68 \\
Down-shift event & $2-1$ & $3-2$ & $4-3$ & $5-4$ & $6-5$ & $7-6$ \\
Vehicle speed (kph) & & 8.72 & 16.95 & 24.05 & 31.99 & 47.30 \\
\hline
\end{tabular}

(b)

Fuel Economy Correlation The experimental mean data, an average of all experimental test data, was calculated for fuel economy comparison. The difference of the cumulative fuel consumption between experiment and baseline simulation was 113.87 grams which translated into a fuel economy difference of 0.012 liter $/ \mathrm{km}$. The simulation result of 3921.26 grams translated to $0.386 \mathrm{liter} / \mathrm{km}$ (6.09 mi/gal) and the experimental average of 3807.39 grams translated to 0.375 liter $/ \mathrm{km}(6.27 \mathrm{mi} / \mathrm{gal})$. The simulation fuel economy result fell within the variation of the experimental data: the minimum 
experimental result was 0.406 liter $/ \mathrm{km}(5.79 \mathrm{mi} / \mathrm{gal})$ and maximum was $0.356 \mathrm{liter} / \mathrm{km}(6.61 \mathrm{mi} / \mathrm{gal})$. The simulation underestimated fuel economy by $2.87 \%$.

Figure 6. Comparison of simulated engine torque and vehicle speed with experimental data-baseline. (a) Engine torque plot with PID (10-0.1-0) control; (b) Engine torque plot with PID (40-0.4-0) control; (c) Vehicle speed traces with PID (40-0.4-0) control.

Engine Torque (Nm)

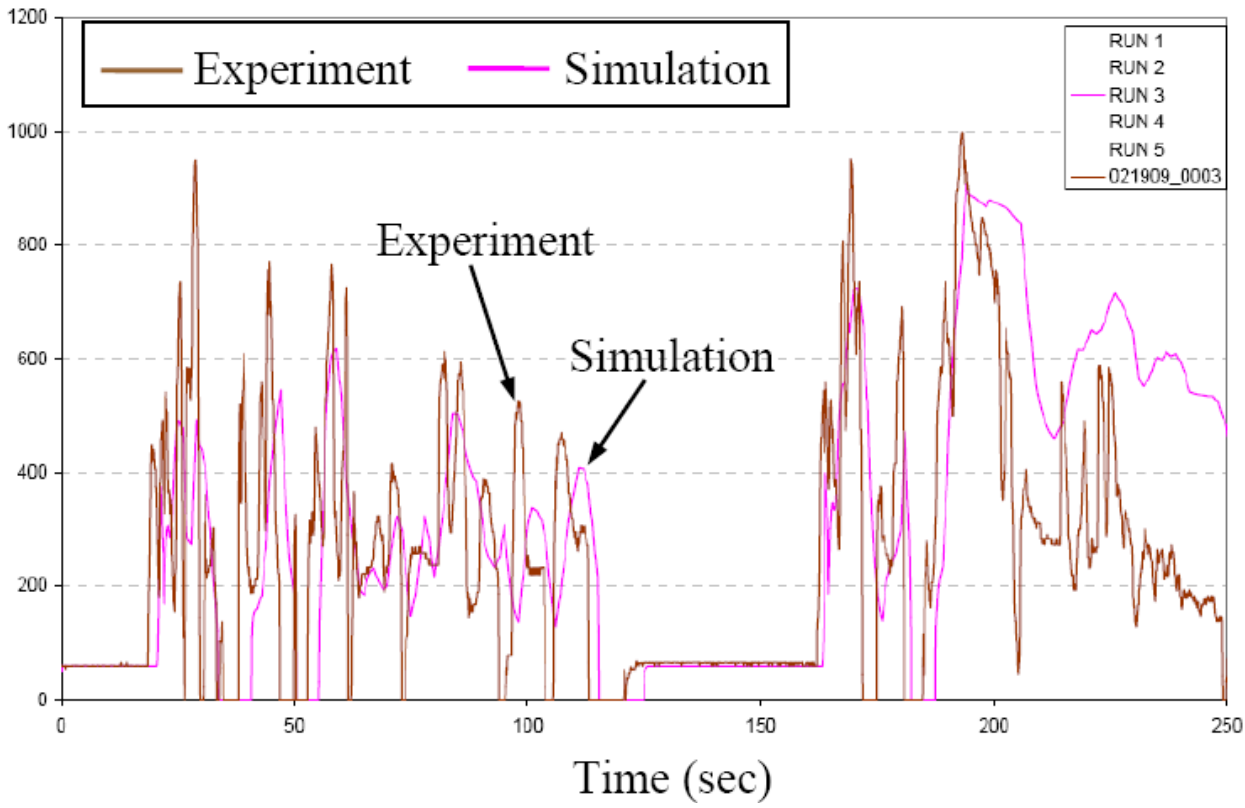

(a)

\section{Engine Torque (Nm)}

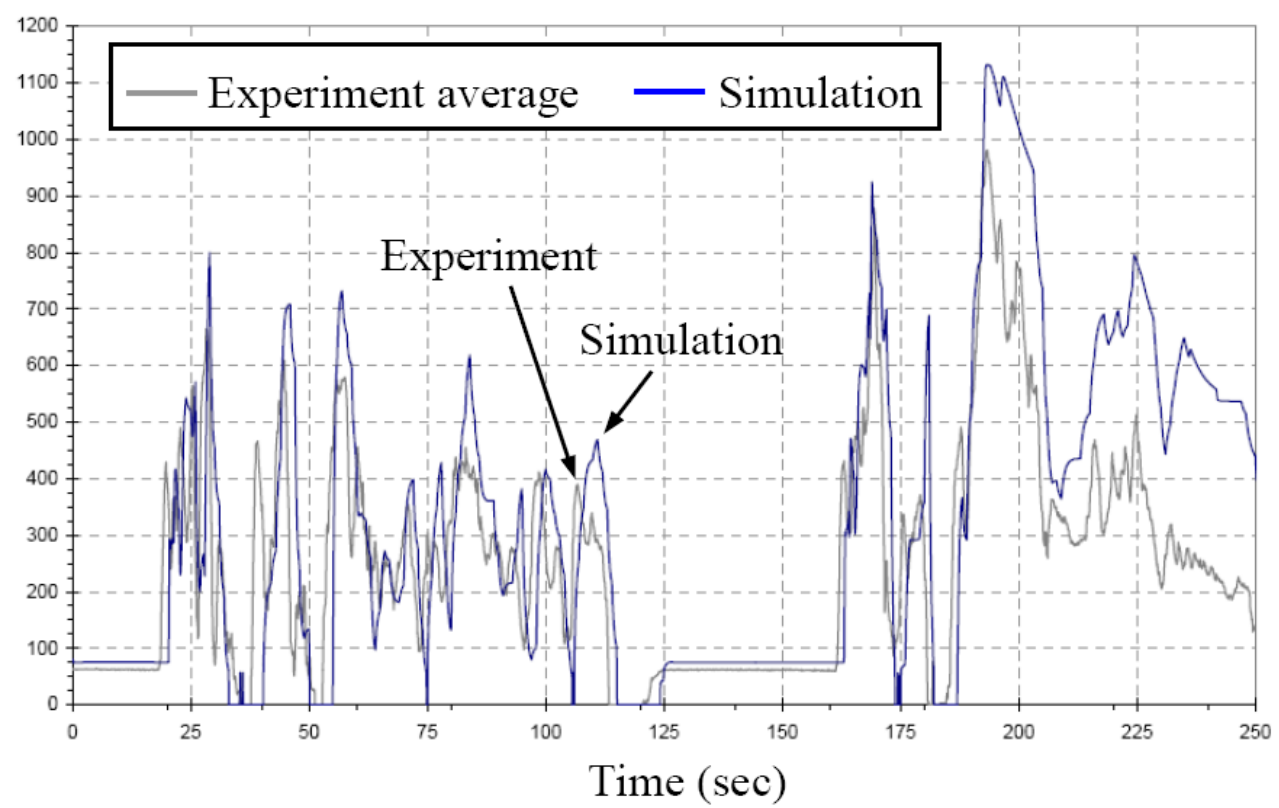

(b) 
Figure 6. Cont.

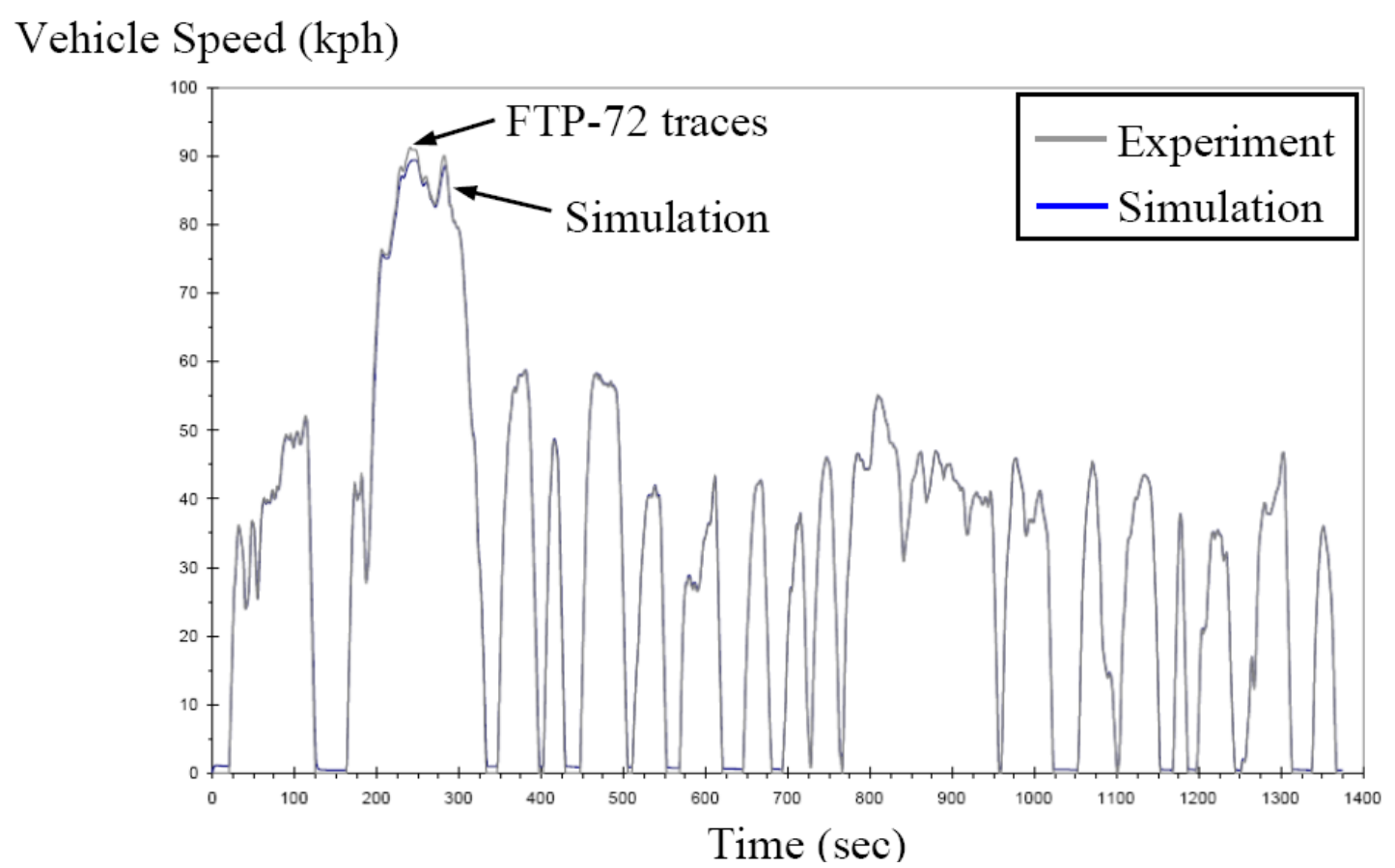

(c)

Figure 7 illustrates that the cumulative fuel consumption of the experimental average and simulation results have significantly different slopes in the time period 200 to 300 second. The cause of this discrepancy is illustrated in Figure 6 (a) and (b) where the simulated torque is considerably larger than the experimental one in the range of 200 to 300 second. Despite significant efforts, this torque difference was not resolved. One feature might separates this 200 to 300 second range from the rest of the drive cycle is vehicle speed. The highest vehicle speed portion (approaching $90 \mathrm{kph}$ ) in the drive cycle is in this time range. The natural thought would be a road load error occurred at higher vehicle speeds. However with the drastic reductions in higher speed, the simulated torque for required road load was still appreciably higher than the experimental average. Three suspicious areas introducing this error might be (1) inaccuracy of ECU data that was collected during experimental testing, (2) some unknown engine or powertrain characteristics that significantly improved efficiency under these operating conditions, or (3) inaccuracy of Equation (3) that resulted in overestimation of engine torque and the torque discrepancy in high vehicle speed portion. Regardless the higher torque in this high speed region is also presented in the simulations of other transmissions, so this torque difference does not impact the comparison results.

\section{Modeling and Simulation of Vehicle with AMT}

With the baseline vehicle model established and correlated to the experimental results, the next step is the application of 12-speed and 10-speed AMTs to the baseline model. Table 4 lists the gear ratio, inertia, efficiency, and shift schedule of the two AMTs. The initial two AMTs shift schedules were the interpolated and extrapolated versions based on of the Allison transmission experimentally derived shift schedule. The simulation results and their comparison are described in the next section. 
Optimization of shift schedule was implemented to minimize the fuel consumption. It is assumed that gear shifting is solely a function of vehicle speed in the simulation [25]. This assumption definitely may generate somewhat unrealistic results or contain shifting points that conflict with drivability and calibration limitations. The results of this vehicle-speed-based optimization should be interpreted as an ideal shifting schedule only from the perspective of the best fuel economy. The objective function was to minimum total fuel consumption over the drive cycle. The simulation systematically varied the shift schedule one gear at a time over the possible range of values. This range was constrained by the neighboring up and down shift points and min and max vehicle speeds at the specific gear. The program searched for the vehicle-speed-based shift point within the specified range that results in the lowest total fuel consumed. The optimization routine then moved to the next gear.

Figure 7. Comparison of simulated fuel consumption with experimental data-baseline vehicle.

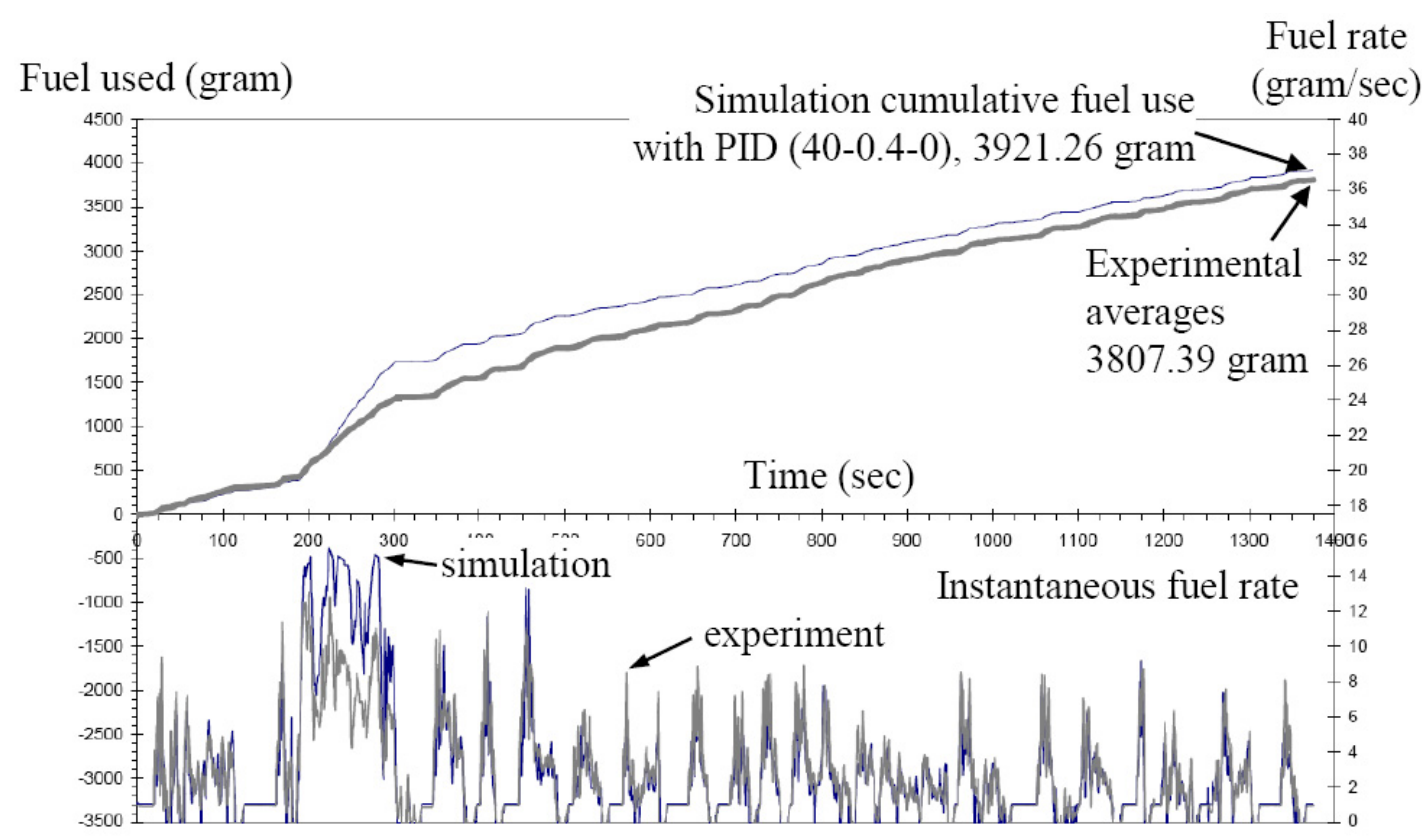

Table 4. Data of two AMTs. (a) Gear ratio and efficiency of 10-speed AMT; (b) Optimal shift schedule of 10-speed AMT; (c) Gear ratio and efficiency of 12-speed AMT; (d) Optimal shift schedule of 12-speed AMT.

\begin{tabular}{ccccc}
\hline Gear No. & Gear Ratio & Gear Ratio Step Fraction & Inertia $\left(\mathbf{k g ~ m}^{\mathbf{2}}\right)$ & Efficiency \\
\hline Lo-Lo & 14.56 & 1.546 & 0.110 & 0.94 \\
Low & 9.420 & 1.510 & 0.150 & 0.95 \\
1 & 6.240 & 1.348 & 0.160 & 0.96 \\
2 & 4.630 & 1.362 & 0.165 & 0.96 \\
3 & 3.400 & 1.344 & 0.180 & 0.96 \\
4 & 2.530 & 1.383 & 0.190 & 0.96 \\
5 & 1.830 & 1.346 & 0.220 & 0.98 \\
6 & 1.360 & 1.360 & 0.290 & 0.98 \\
7 & 1.000 & 1.351 & 0.400 & 0.99 \\
8 & 0.740 & & 0.700 & 0.98 \\
\hline
\end{tabular}

(a) 
Table 4. Cont.

\begin{tabular}{lccccccccc}
\hline \multicolumn{10}{c}{ Vehicle Speed Based Shift Schedule-Optimization } \\
\hline Up-shift event & $1-2$ & $2-3$ & $3-4$ & $4-5$ & $5-6$ & $6-7$ & $7-8$ & $8-9$ & $9-10$ \\
Vehicle speed (kph) & 4.69 & 7.44 & 11.43 & 15.07 & 21.69 & 29.15 & 41.18 & 55.35 & 63.99 \\
Down-shift event & $2-1$ & $3-2$ & $4-3$ & $5-4$ & $6-5$ & $7-6$ & $8-7$ & $9-8$ & $10-9$ \\
Vehicle speed (kph) & 4.26 & 6.85 & 9.23 & 12.57 & 16.72 & 25.68 & 39.84 & 41.15 & 58.68 \\
\hline
\end{tabular}

(b)

\begin{tabular}{|c|c|c|c|c|}
\hline Gear No. & Gear Ratio & Gear Ratio Step Fraction & Inertia $\left(\mathrm{kg} \mathrm{m}^{2}\right)$ & Efficiency \\
\hline 1 & 12.326 & 1.285 & 0.118 & 0.95 \\
\hline 2 & 9.590 & 1.290 & 0.186 & 0.95 \\
\hline 3 & 7.435 & 1.285 & 0.123 & 0.95 \\
\hline 4 & 5.784 & 1.267 & 0.195 & 0.96 \\
\hline 5 & 4.565 & 1.296 & 0.137 & 0.96 \\
\hline 6 & 3.522 & 1.304 & 0.218 & 0.96 \\
\hline 7 & 2.700 & 1.285 & 0.155 & 0.97 \\
\hline 8 & 2.101 & 1.290 & 0.247 & 0.97 \\
\hline 9 & 1.629 & 1.286 & 0.225 & 0.98 \\
\hline 10 & 1.267 & 1.267 & 0.362 & 0.98 \\
\hline 11 & 1.000 & 1.285 & 0.406 & 0.99 \\
\hline 12 & 0.778 & & 0.662 & 0.98 \\
\hline
\end{tabular}

(c)

\begin{tabular}{lcccccccccccc}
\hline \multicolumn{10}{c}{ Vehicle Speed Based Shift Schedule-Optimization } \\
\hline $\begin{array}{l}\text { Up-shift event } \\
\begin{array}{l}\text { Vehicle speed } \\
\text { (kph) }\end{array}\end{array}$ & $1-2$ & $2-3$ & $3-4$ & $4-5$ & $5-6$ & $6-7$ & $7-8$ & $8-9$ & $9-10$ & $10-11$ & $11-12$ \\
$\begin{array}{l}\text { Down-shift } \\
\text { event }\end{array}$ & $2-1$ & $3-2$ & $4-3$ & $5-4$ & $6-5$ & $7-6$ & $8-7$ & $9-8$ & $10-9$ & $11-10$ & $12-11$ \\
$\begin{array}{l}\text { Vehicle speed } \\
(\mathrm{kph})\end{array}$ & 4.23 & 5.75 & 7.39 & 9.37 & 12.29 & 15.83 & 24.48 & 31.49 & 43.13 & 50.80 & 63.14 \\
\hline
\end{tabular}

(d)

The entire set of up-shift and down-shift points were evaluated after each iteration. The evaluation was based on the assumption of the gear independence, meaning changing one gear shifting point would not affect the fuel consumption on other gears. This is a limiting assumption which re-iterates the solution sets and changes all initial values to the new optimized values. The iterations continued until convergence. The convergence was a subjective measurement, not to an exact number. Convergence typically appeared after the third or fourth iteration of the optimization, such as the Allison transmission optimization was converged with three iterations.

A simulation was performed using the baseline Allison transmission to compare the differences of fuel economy between an optimized shift schedule and the experimental one. To start the optimization, the initial values must be defined for all up and down shift points. For the Allison transmission, this shift schedule was already determined by statistical averaging of the experimental data. For the other 
two AMTs, the initial shift schedules were created mainly based on the Allison transmission shift schedule.

During shift schedule optimization of some gears, the objective function was relatively flat. In other words, the total fuel consumption varied within 0.5 to 1.0 gram over some portion of the possible vehicle speed range. This might be due to that available shift points were limited by small range of the vehicle speed in certain gears and therefore the objective function quickly reached convergence. The nature of certain gears having insignificant influence on fuel consumption means that in the real world these shift points could be modified for drivability without having a measurable impact on fuel economy.

\section{Comparisons of Fuel Economy Simulation Results}

The optimized shift schedules were run over the FTP-72 drive cycle. Result indicated a 1.64\% (64.12 gram) end-of-cycle improvement between the simulation of baseline Allison shift schedule and the optimized one. As mentioned previously, the baseline Allison transmission shift schedule consumed 3921.26 grams which translates to 0.386 liter $/ \mathrm{km}(6.09 \mathrm{mi} / \mathrm{gal})$. The optimal shift schedule consumed 3857.14 grams which translates to 0.380 liter $/ \mathrm{km}(6.19 \mathrm{mi} / \mathrm{gal})$. A simulation result of the optimal shift schedule underestimates fuel economy by $1.28 \%$ comparing to the experimental average of 0.375 liter $/ \mathrm{km}(6.27 \mathrm{mi} / \mathrm{gal})$.

Additional fuel economy comparison was two AMTs. To ensure a fair comparison, the optimized shift schedule of the Allison was used for comparison with the two AMTs. Compared with the optimized Allison shift schedule, the 10-speed AMT showed a 14.5\% improvement and the 12-speed AMT showed a $12.2 \%$ improvement in fuel economy. This translated to $0.9 \mathrm{mi} / \mathrm{gal}$ improvement with the 10-speed AMT and $0.76 \mathrm{mi} / \mathrm{gal}$ improvement with the 12-speed AMT over the FTP-72 drive cycle. Figure 8 presents the comparisons of fuel consumption of optimized shift schedule of the Allison and two AMTs.

Figure 8. Comparison of fuel consumption based on optimized shift schedules.

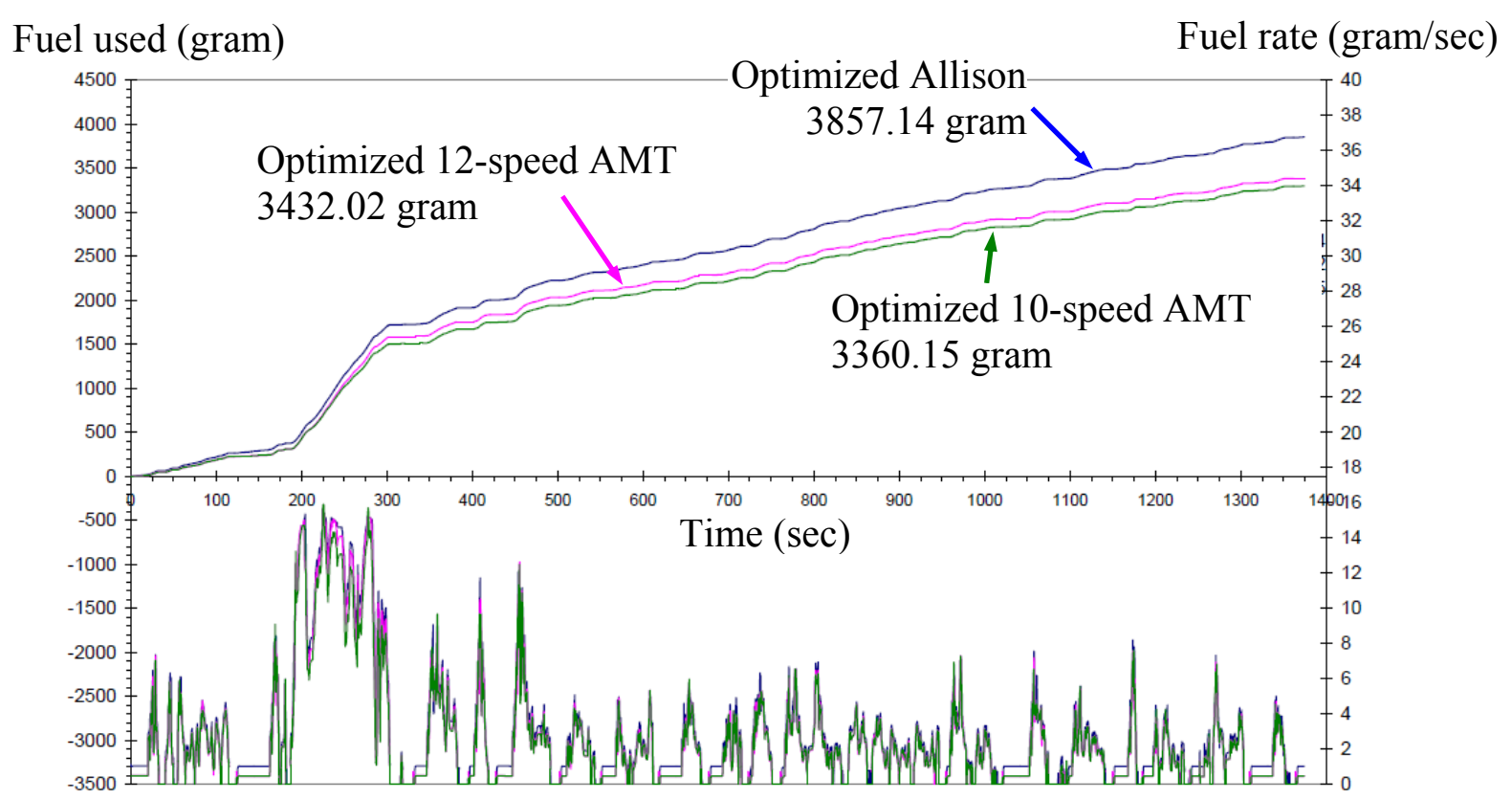


The fuel economy improvements of the engine idle stop/start and B-ISG system used baseline simulation results (seven-speed AT) as a comparison base. For component-level modeling (such as electric air conditioner), a composite sum of electrical and mechanical accessory loads was adjusted to correspond with the changes on electric and engine loads. Simulation of the LMTV with an integrated automatic engine stop/start system showed a 3.39\% improvement in fuel economy. A B-ISG mild hybridization system and full accessory electrification showed a 10.2\% improvement in fuel economy when compared to the baseline model. Table 5 summarizes the fuel economy comparisons between experimental average data, simulated results of baseline Allison, optimized shift schedule of Allison, two AMTs, engine idle stop/start, and B-ISG mild hybridization.

\section{Conclusions}

The focus of this study is the feasibility analysis and evaluation of AMT and mild hybridization powertrain that have potential to improve the fuel economy of the LMTV M1078 A1 2.5-ton cargo trucks. Two AMTs, 10-speed and 12-speed, were evaluated in the study. The powertrain hybridization included a stop/start system followed by a B-ISG mild hybrid system. This study utilized a combination of on-road experimental vehicle data and analytical vehicle model and simulation. The GT-Drive software was used for the vehicle modeling and simulation in this project. This paper presents the results of (1) establishment of a validated, high fidelity baseline analytical vehicle model, (2) modeling and simulation of two AMTs and their control strategy, (3) optimization of transmissions shift schedules, and (4) modeling and simulation of engine idle stop/start and B-ISG systems to improve the fuel economy.

Table 5. Comparison of fuel economy over the FTP-72 drive cycle.

\begin{tabular}{lccc}
\hline & $\begin{array}{c}\text { Total Fuel Used } \\
\text { (gram) }\end{array}$ & $\begin{array}{c}\text { Fuel Economy } \\
\text { liter/km (mi/gal) }\end{array}$ & \% Improvement \\
\hline Experimental average & 3807.39 & $0.375(6.27)$ & \\
Allison baseline & 3921.26 & $0.386(6.09)$ & \\
Allison optimized shift schedule & 3857.14 & $0.380(6.19)$ & 1.64 \\
10-speed AMT & 3360.15 & $0.331(7.09)$ & 14.5 \\
12-speed AMT & 3432.02 & $0.338(6.95)$ & 12.2 \\
\hline Allison baseline & 3921.26 & $0.386(6.09)$ & \\
Engine idle stop/start & 3788.47 & $0.373(6.31)$ & 3.4 \\
B-ISG mild hybridization & 3521.86 & $0.347(6.72)$ & 10.2 \\
\hline
\end{tabular}

The simulated fuel economy for the baseline LMTV run over the FTP-72 drive cycle was $0.386 \mathrm{liter} / \mathrm{km}(6.09 \mathrm{mi} / \mathrm{gal})$ while the experimental average of fuel economy was $0.375 \mathrm{liter} / \mathrm{km}$ (6.27 mi/gal). The simulation result fell within the variation of the experimental data: the minimum experimental result was 0.406 liter $/ \mathrm{km}(5.79 \mathrm{mi} / \mathrm{gal})$ and maximum was $0.356 \mathrm{liter} / \mathrm{km}$ (6.61 mi/gal). The simulation underestimated fuel economy by $2.87 \%$. The fuel economy of optimal shift schedule for Allison transmission resulted in 0.380 liter $/ \mathrm{km}$ (6.19 mi/gal) which had a higher accuracy (than baseline) correlated to the experimental data. A simulation result of the optimal shift schedule underestimates fuel economy by $1.28 \%$ comparing to the experimental average. 
Compared with the Allison optimized shift schedule, the simulated fuel economy was 0.331 liter $/ \mathrm{km}$ (7.09 mi/gal) of 10-speed AMT which indicated a 14.5\% improvement. The 12-speed AMT showed a $12.2 \%$ improvement in fuel economy comparing to optimal shift Allison transmission. The integration of a stop/start system followed by a B-ISG mild hybrid system incorporating regenerative braking was estimated to improve fuel economy $3.39 \%$ and $10.2 \%$ respectively comparing to baseline simulation results (seven-speed AT). Considerations such as packaging, durability, or manufacturing were outside the scope of this study.

\section{Acknowledgements}

The authors would like to acknowledge the technical and financial support of the National Automotive Center (NAC) located within the US Army Tank-Automotive Research, Development and Engineering Center (TARDEC). In particular, Paul Skalny provided technical guidance related to the LMTV fuel saving program goals, and Matt Van Benschoten in Roush Industry conducted the experiments. Finally, the authors would like to thank the management of World Technical Services, Inc., ASRC Federal Holding Company, for their support of this publication.

\section{References}

1. U.S. Department of Defense. More Capable War Fighting through Reduced Fuel Burden; Technical Report for Office of the Under Secretary of Defense for Acquisition; Technology and Logistics: Washington, DC, USA, May 2001.

2. Muradian, V. Interview with Terry Pudas, Acting Deputy Assistant Secretary of Defense for Forces, Transformation and Resources. Defense News, 22 January 2007, p. 22.

3. Karbuz, S. US military energy consumption-facts and figures. Available online: http://www.energybulletin.net/node/29925/ (accessed on 18 October 2010).

4. BAE Systems. Available online: http://www.baesystems.com/Newsroom/ (accessed on 26 January 2011).

5. FMTV A1R M1078A1 data sheet, BAE Systems. Available online: http://www.baesystems.com/ BAEProd/groups/public/documents/bae_publication/bae_pdf_mps_fmtv_m1078a1.pdf/ (accessed on 30 October 2010).

6. Kuroiwa, H.; Ozaki, N.; Okada, T.; Yamasaki, M. Next-generation fuel-efficient automated manual transmission. SAE Paper 2004, 53, 205-209.

7. Heath, R.P.; Child, A.J. A seamless automated manual transmission (AMT) with no torque interrupt. SAE Paper 2007, doi: 10.4271/2007-01-1307.

8. Yamamoto, K.; Aoki, T. Analysis of the influence on fuel economy by transmission type and the estimation of fuel economy. Jpn. Sci. Technol. Agency 2000, 12, 63-72.

9. Song, X.Y.; Sun, Z.X.; Yang, X.J.; Zhu, G.M. Modelling, control, and hardware-in-the-loop simulation of an automated manual transmission. Proc. Inst. Mech. Eng. D J. Automobile Eng. 2010, 224, 143-160.

10. Zhang, Y.; Chen, X.; Zhang, X.; Jiang, H.; Tobler, W. Dynamic modeling and simulation of a dual-clutch automated lay-shaft transmission. ASME J. Mech. Des. 2005, 127, 302-307. 
11. Kusumi, H.; Yagi, K.; Ny, Y.; Abo, S.; Furuta, S.; Morikawa, M. 42V power control system for Mild Hybrid Vehicle (MHV). SAE Paper 2002, doi: 10.4271/2002-01-0519.

12. Tamai, G.; Jeffers, M.; Lo, C.; Thurston, C.; Tarnowsky, S.; Poulos, S. Development of the hybrid system for the Saturn VUE hybrid. SAE Paper 2006, doi: 10.4271/2006-01-1502.

13. Canova, M.; Sevel, K.; Guezennec, Y.; Yukovich, S. Control of the start/stop of a diesel engine in a parallel HEV with a belted starter/alternator. SAE Paper 2007, doi: 10.4271/2007-24-0076.

14. Evans, D.; Polom, M.; Poulos, S.; VanMaanen, K.; Zarger, T. Powertrain architecture and controls integration for GM's hybrid full-size pickup truck. SAE Paper 2003, doi: 10.4271/200301-0085.

15. Chen, X.; Shen, S. Comparison of two permanent-magnet machines for a mild hybrid electric vehicle application. SAE Paper 2008, doi: 10.4271/2008-01-1552.

16. Hanada, K.; Kaizuka, M.; Ishikawa, S.; Imai, T.; Matsuoka, H.; Adach, H. Development of a hybrid system for the V6 midsize sedan. SAE Paper 2005, doi: 10.4271/2005-01-0274.

17. Kabasawa, A.; Takahashi, K. Development of the IMA motor for the V6 hybrid midsize sedan. SAE paper 2005, doi: 10.4271/2005-01-0276.

18. van Benschoten, M.; Nelson, E. FMTV transmission fuel economy study: Evaluation of AMT performance using experimental and analytical methods. In Proceedings of the 2009 Ground Vehicle Systems Engineering and Technology Symposium (GVSETS), Detroit, MI, USA, 28 May 2009.

19. GT-Drive, Gamma Technologies, Inc. Virtual Engine/Powertrain/Vehicle Simulation. Available online: http://www.gtisoft.com/GT-SUITE_Product.html/ (accessed on 15 October 2010).

20. Hausberger, S.; Rexeis, M. Emission behaviour of modern heavy duty vehicles in real world driving. Int. J. Environ. Pollut. 2004, 22, 275-286.

21. Ward, M.; Brace, C.; Hale, T.; Ceen, R. Investigation of sweep mapping approach on engine testbed. SAE Paper 2002, doi: 10.4271/2002-01-0615.

22. Pacejka, H.B. Tyre and Vehicle Dynamics; Butterworth-Heineman: Oxford, UK, 2002.

23. Hucho, W.H. Aerodynamics of Road Vehicles; SAE International: Troy, MI, USA, 1998.

24. U.S. Environmental Protection Agency. Testing and Measuring Emissions. Available online: http://www.epa.gov/nvfel/testing/ dynamometer.html/ (accessed on 12 October 2010).

25. Ivarsson, M.; Slund, J.; Nielsen, L. Impacts of AMT gear-shifting on fuel optimal look ahead control. SAE Paper 2010, doi: 10.4271/2010-01-0370.

(C) 2011 by the authors; licensee MDPI, Basel, Switzerland. This article is an open access article distributed under the terms and conditions of the Creative Commons Attribution license (http://creativecommons.org/licenses/by/3.0/). 